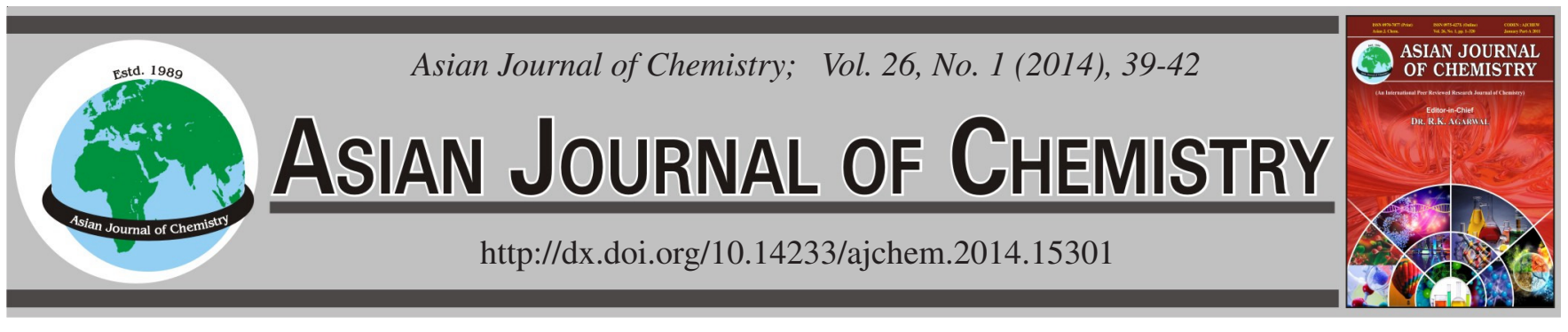

\title{
Absorption of Carbon Dioxide in Ethanolamine Solutions
}

\author{
Yanyue Lu*, Anping Liao, Zhuge Yun, Yanging Liang and Qinmei Yao
}

Key Laboratory of Chemical and Biological Transforming Process, Guangxi Key Laboratory of Chemistry and Engineering of Forest Products, College of Chemistry and Chemical Engineering, Guangxi University for Nationalities, Nanning 530006, P.R. China

*Corresponding author: Tel: +86 771 3260558; E-mail: luyanyue@163.com

Received: 11 February 2013;

Accepted: 7 May 2013;

Published online: 26 December 2013;

AJC-14469

Ethanolamine solutions are a kind of important absorbent for carbon dioxide capture from flue gas. In this work, the absorption rate and absorption capacity of carbon dioxide by ethanolamine and piperazine solutions have been studied. Using a newly absorption equipment, the absorption rate was measured in monoethanolamine, diethanolamine and piperazine solutions with different concentration from 10 to $50 \mathrm{wt} \%$, respectively. The experimental results showed that monoethanolamine and diethanolamine both have a large absorption rate and capacity. According to the experimental results and the zwitterion mechanism, the kinetics of the reaction between carbon dioxide and ethanolamine could be derived.

Keywords: Carbon dioxide, Absorption rate, Ethanolamine, Piperazine, Kinetics.

\section{INTRODUCTION}

Carbon dioxide is a major greenhouse gas which can induce the global warming with increasing emission by human activity. To reduce carbon dioxide emission has become a worldwide problem. The fossil fuel combustion is the largest sources of man-made carbon dioxide. Therefore, the development of technology is necessary in order to remove and recover $\mathrm{CO}_{2}$ from these emission sources.

Chemical absorption is the most widely used method. Paul and Thomas ${ }^{1}$ studied the absorption of $\mathrm{CO}_{2}$ into aqueous potassium salt of proline, their experimental results was used to interpret the kinetics of the reaction of $\mathrm{CO}_{2}$ with potassium salt of proline. Mortaheb et al. ${ }^{2}$ have investigated the absorption of $\mathrm{CO}_{2}$ in water-in-oil (w/o) emulsions, the results show that the absorption rate and capacity for monoethanolamine emulsion is higher compared to those for diethanolamine emulsion. A series of tests were conducted by Liu et al. ${ }^{3,4}$ for the absorption of carbon dioxide in aqueous ammonia. In their further work, the kinetics and mass transfer of $\mathrm{CO}_{2}$ absorption into aqueous ammonia were also investigated. Portugal et al. ${ }^{5}$ investigated the absorption of carbon dioxide in aqueous solution of potassium threonate. Derks et al. ${ }^{6}$ have been studied the absorption of carbon dioxide into aqueous piperazine (PZ) solutions and given the kinetics of the reaction between $\mathrm{CO}_{2}$ and piperazine in aqueous solution.

Previous studies showed that the aqueous ethanolamine solutions such as monoethanolamine (MEA), diethanolamine (DEA) are frequently used for removal of carbon dioxide from various flue gases. The advantage of using ethanolamine as absorbent is due to its fast reaction kinetics with $\mathrm{CO}_{2}$, high selectivity, low hydrocarbon solubility and low solvent cost. Piperazine also is a common absorbent, which is used principally as active agents to activate ethanolamine solutions. However, the absorption rate and reaction kinetics of $\mathrm{CO}_{2}$ in ethanolamine and piperazine solutions are not still absolutely clear. More researches should be done to reveal the characteristic of these absorbent. Therefore, this paper will focus on the experimental research of carbon dioxide absorption in ethanolamine and piperazine solutions at different concentrations. Absorption data obtained from experiment will be used to determine the kinetics of the reaction between $\mathrm{CO}_{2}$ and ethanolamine.

\section{EXPERIMENTAL}

$\mathrm{CO}_{2}\left(99.995 \%\right.$ purity), nitrogen $\left(\mathrm{N}_{2}, 99.996 \%\right.$ purity) were obtained from Langtian Co., China. Monoethanolamine (MEA, $\geq 99 \%$ purity), diethanolamine (DEA, $\geq 99 \%$ purity) and Piperazine (PZ, $\geq 99 \%$ purity) were purchased from Guangyao Chemicals, China. All chemicals were reagent grade and used without further purification. Deionized water was used.

Experimental procedure: The schematic diagram of the absorption equipment applied in this study is shown in Fig. 1. The main part of the setup consist of a batch reactor equipped with a magnetic stirrer, $\mathrm{CO}_{2}$ cylinder with pressure control, thermocouple, gas flowmeter and a heating/cooling jacket with a constant temperature bath. 


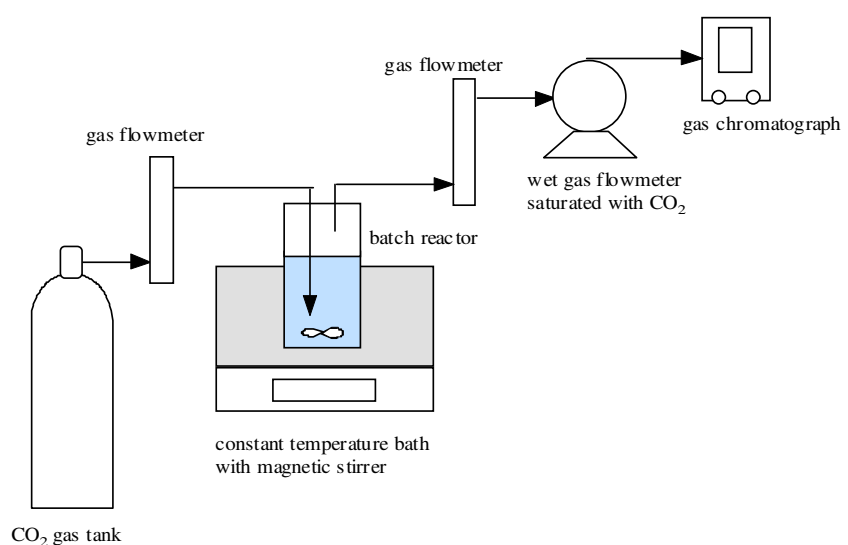

Fig. 1. Schematic diagram of the experimental setup

The absorbents used in the system were monoethanolamine, diethanolamine and piperazine, respectively. Their solution concentrations were in the range of $10-50 \mathrm{wt} \%$. The volume of the absorbent solution in reactor was $300 \mathrm{~mL}$. The temperature of absorption was controlled at the desired level by immersing the reactor into the constant temperature bath. In a typical experiment, the absorption reaction was initiated by feeding $\mathrm{CO}_{2}$ gas into the reactor from the $\mathrm{CO}_{2}$ cylinder. The inlet $\mathrm{CO}_{2}$ volumetric flow rate was maintained at $0.1 \mathrm{~L} / \mathrm{h}$ by using a pressure controller and volumetric flow rate controller. The outlet $\mathrm{CO}_{2}$ gas would be measured and recorded in $30 \mathrm{~s}$ time intervals using a volumetric flow meter. Then the corresponding absorption rate of $\mathrm{CO}_{2}$ in the ethanolamine and piperazine solutions was determined from the difference of inlet and outlet flow rate of the reactor. When the outlet measurements reached steady state, it indicated that the aqueous absorbent solutions were saturated with $\mathrm{CO}_{2}$ and the inlet gas flow would be stopped. The absorption capacity of $\mathrm{CO}_{2}$ in each absorbent solution was determined by using a wet gas flowmeter which was saturated with $\mathrm{CO}_{2}$ in advance. It can calculate the amount of absorbed gas into the absorbent solutions.

\section{RESULTS AND DISCUSSION}

Absorption into monoethanolamine solutions: Monoethanolamine was used as absorbent in this case. The absorption rate and capacity of $\mathrm{CO}_{2}$ in monoethanolamine solution were measured at the pressure of $101 \mathrm{kPa}$ and the temperature of $298.15 \mathrm{~K}$. The investigated monoethanolamine concentrations were 10, 20, 30, 40 and 50 wt \%, respectively. Fig. 2 shows the comparison of the absorption rate of $\mathrm{CO}_{2}$ between different monoethanolamine solution concentrations.

From the figure, it can be observed that the absorption rate and capacity of $\mathrm{CO}_{2}$ increase with increasing monoethanolamine concentration. In low concentration range of 10-20 wt $\%$, there is an apparent difference between the absorption rates of $\mathrm{CO}_{2}$ in monoethanolamine solution. However the difference between the absorption rates is decreased at high monoethanolamine concentration. The curves of absorption rates at concentration of 40 and $50 \mathrm{wt} \%$ are very close to each other, it indicate that increasing monoethanolamine concentration have a limited role in increasing the absorption rates of $\mathrm{CO}_{2}$. The monoethanolamine solutions with the concentration

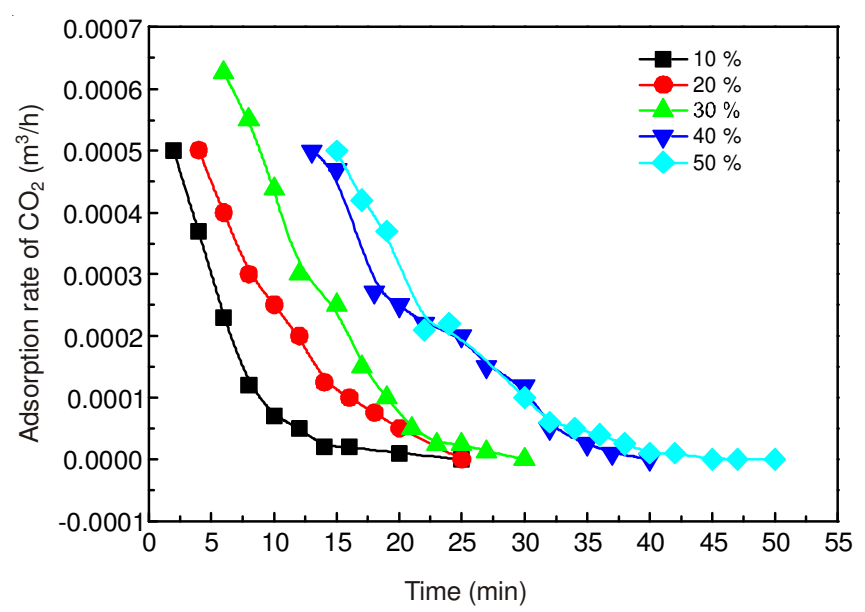

Fig. 2. Absorption rate of $\mathrm{CO}_{2}$ in monoethanolamine solutions with different concentration

ranging from 10 to $30 \mathrm{wt} \%$ reached quickly saturation after 20 min reaction time. The results indicate that the absorption capacity of monoethanolamine solution is low when its concentration is in this range. While the monoethanolamine solutions with the concentration of 40 and $50 \mathrm{wt} \%$ reached saturation after $40 \mathrm{~min}$ reaction time. From the experimental results, it can be concluded that increasing monoethanolamine concentration would improve the absorption rate and capacity of $\mathrm{CO}_{2}$. However the absorption rate and capacity increases slowly at the high monoethanolamine concentration. Therefore, the best monoethanolamine concentration should be selected from 40 to $50 \mathrm{wt} \%$.

Absorption into diethanolamine solutions: Diethanolamine was used as absorbent in this case. The absorption rate and capacity of $\mathrm{CO}_{2}$ in diethanolamine solution were measured at the pressure of $101 \mathrm{kPa}$ and the temperature of $298.15 \mathrm{~K}$. The investigated diethanolamine concentrations were 10, 20, 30, 40 and $50 \mathrm{wt} \%$, respectively. Fig. 3 shows the comparison of the absorption rate of $\mathrm{CO}_{2}$ between different diethanolamine solution concentrations.

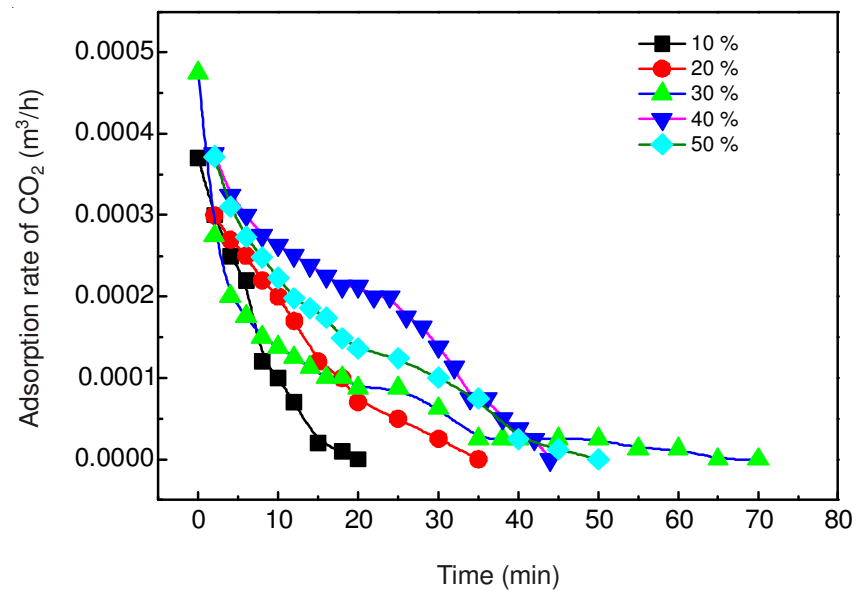

Fig. 3. Absorption rate of $\mathrm{CO}_{2}$ in diethanolamine solutions with different concentration

As shown in Fig. 3, the absorption rate and capacity of $\mathrm{CO}_{2}$ is increased with the diethanolamine concentration increasing. There is a less difference between the absorption rates of $\mathrm{CO}_{2}$ in high concentration range. The diethanolamine 
solutions with the concentration of 10 and $20 \mathrm{wt} \%$ reached saturation after $0.5 \mathrm{~h}$ reaction time. While the solutions with the concentration ranging from 30 to $50 \mathrm{wt} \%$ reached saturation after $50 \mathrm{~min}$ reaction time. Comparison the experiment results of Fig. 3 with that of Fig. 2, it can be observed that the diethanolamine solutions have a higher absorption capacity than monoethanolamine solutions. The absorption rate and capacity increases slowly at the high diethanolamine concentration. Therefore, the best diethanolamine concentration should be selected from 40 to 50 wt $\%$.

Absorption into piperazine solutions: Piperazine was used as absorbent in this case. The investigated piperazine concentrations were 10, 20, 30, 40, $50 \mathrm{wt} \%$, respectively. Fig. 4 shows the comparison of the absorption rate of $\mathrm{CO}_{2}$ between different piperazine solution concentrations.

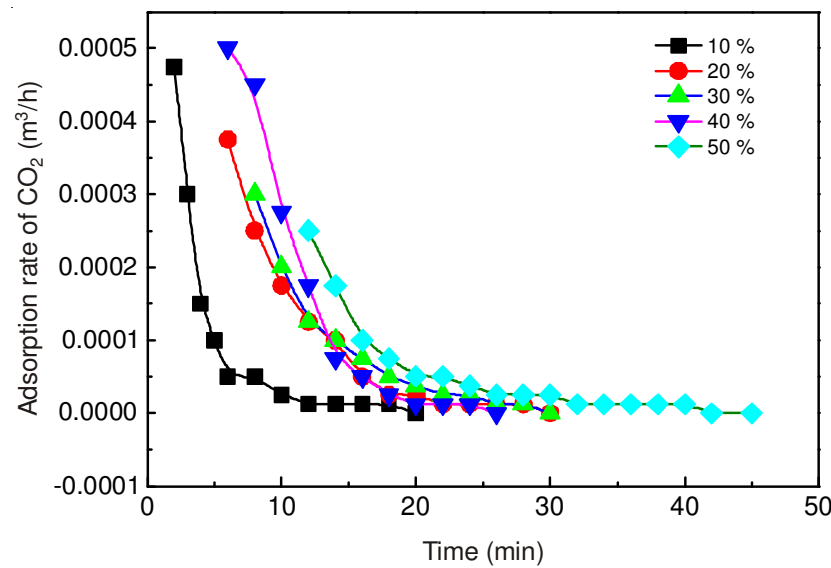

Fig. 4. Absorption rate of $\mathrm{CO}_{2}$ in piperazine solutions with different concentration

As shown in Fig. 4, the absorption rate and capacity of $\mathrm{CO}_{2}$ is increased with the concentration of piperazine. There is a less difference between the absorption rates of $\mathrm{CO}_{2}$ in high concentration range. The piperazine solutions with the concentration of $10 \mathrm{wt} \%$ reached quickly saturation after $5 \mathrm{~min}$ reaction time. While the solutions with the concentration ranging from 20 to $50 \mathrm{wt} \%$ reached saturation after $20 \mathrm{~min}$ reaction time. The best diethanolamine concentration should be selected from 40 to $50 \mathrm{wt} \%$. Compared to the ethanolamine absorbent, piperazine have a lower absorption rate and capacity. It is used principally as active agents to activate ethanolamine solutions.

Performance comparisons: The above experiment results show that the best absorbents concentration should be selected from 40 to $50 \mathrm{wt} \%$ in ethanolamine or piperazine solutions. In order to assess the absorption performance of each absorbent at identical concentrations, each absorbent solution concentration was kept at 40 and $50 \mathrm{wt} \%$, respectively. The comparison of the absorption rate of $\mathrm{CO}_{2}$ between different absorbents was shown in Figs. 5 and 6.

From the comparison results, it can be conclude that monoethanolamine have the highest absorption rate among these absorbents, followed by the diethanolamine. At these two concentrations, monoethanolamine and diethanolamine reached saturation after 40 min reaction time, while piperazine was in 20 min reaction time. It indicated that monoethanolamine and diethanolamine both have a large absorption capacity.

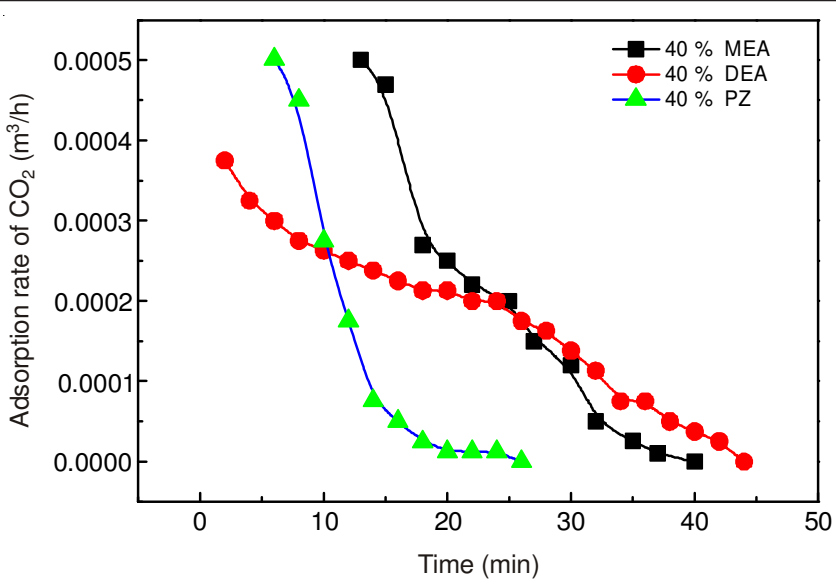

Fig. 5. Comparison of absorption rate of $\mathrm{CO}_{2}$ in three absorbents with concentration of 40 wt \%

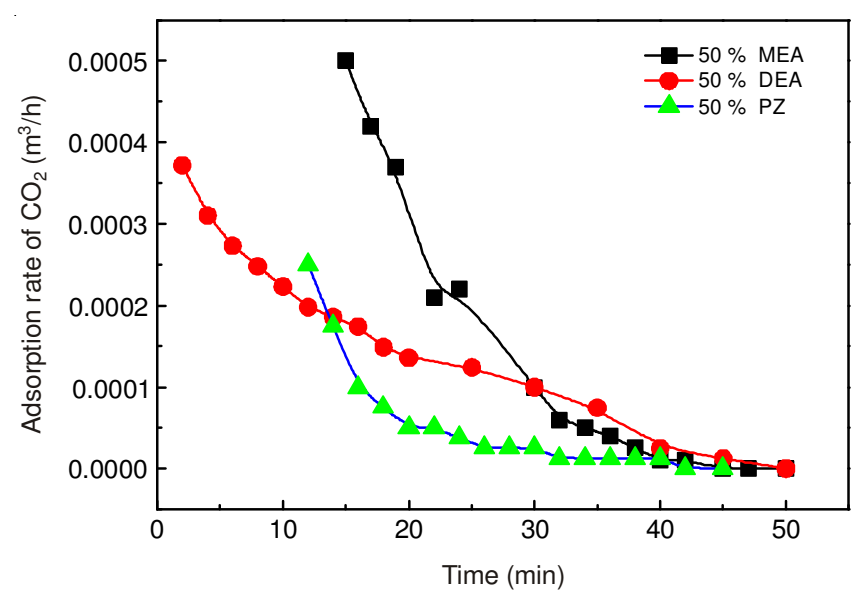

Fig. 6. Comparison of absorption rate of $\mathrm{CO}_{2}$ in three absorbents with concentration of $50 \mathrm{wt} \%$

Kinetics of $\mathrm{CO}_{2}$ with ethanolamine: The following reactions may take place when $\mathrm{CO}_{2}$ is absorbed into the ethanolamine solution (where, $\mathrm{R}_{1}=\mathrm{CH}_{2} \mathrm{CH}_{2} \mathrm{OH}, \mathrm{R}_{2}=\mathrm{H}$ or $\mathrm{CH}_{3}$ or $\mathrm{CH}_{2} \mathrm{CH}_{2} \mathrm{OH}$ ).

$$
\begin{array}{r}
\mathrm{CO}_{2}+2 \mathrm{H}_{2} \mathrm{O} \underset{\mathrm{k}_{-1}}{\stackrel{\mathrm{k}_{1}}{\longrightarrow}} \mathrm{HCO}_{3}^{-}+\mathrm{H}_{3} \mathrm{O}^{+}, \mathrm{K}_{1}=\frac{\mathrm{k}_{1}}{\mathrm{k}_{-1}} \\
\mathrm{~K}_{2}+\mathrm{R}_{1} \mathrm{R}_{2} \mathrm{NH} \underset{\mathrm{k}_{-2}}{\stackrel{\mathrm{k}_{2}}{\longrightarrow}} \mathrm{R}_{1} \mathrm{R}_{2} \mathrm{NH}^{+} \mathrm{COO}^{-}+\mathrm{H}_{3} \mathrm{O}^{+}, \\
\mathrm{R}_{1} \mathrm{R}_{2} \mathrm{NH}^{+} \mathrm{COO}^{-}+\mathrm{R}_{1} \mathrm{R}_{2} \mathrm{NH} \underset{\mathrm{k}_{-3}}{\stackrel{\mathrm{k}_{3}}{\longrightarrow}} \mathrm{R}_{1} \mathrm{R}_{2} \mathrm{NH}_{2}^{+} \\
+\mathrm{R}_{1} \mathrm{R}_{2} \mathrm{NCOO}^{-}, \mathrm{K}_{3}=\frac{\mathrm{k}_{3}}{\mathrm{k}_{-3}} \\
\mathrm{R}_{1} \mathrm{R}_{2} \mathrm{NH}^{+} \mathrm{COO}^{-}+\mathrm{H}_{2} \mathrm{O} \underset{\mathrm{k}_{4}}{\longrightarrow} \mathrm{H}_{3} \mathrm{O}^{+} \\
+\mathrm{R}_{1} \mathrm{R}_{2} \mathrm{NCOO}^{-}, \mathrm{K}_{4}=\frac{\mathrm{k}_{4}}{\mathrm{k}_{-4}}
\end{array}
$$

The zwitterion mechanism was found to be suitable for modeling the absorption of $\mathrm{CO}_{2}$ into ethanolamine solutions. This absorption reaction involves the formation of zwitterion 
$\left(\mathrm{R}_{1} \mathrm{R}_{2} \mathrm{NH}^{+} \mathrm{COO}^{-}\right)$and subsequent deprotonation of zwitterion by a base to produce carbamate $\left(\mathrm{R}_{1} \mathrm{R}_{2} \mathrm{NCOO}^{-}\right)$and protonated base $\left(\mathrm{R}_{1} \mathrm{R}_{2} \mathrm{NH}_{2}^{+}\right)$, followed by carbamate reversion by hydrolysis ${ }^{7}$.

The total reaction of ethanolamine solutions absorb carbon dioxide can be described as the eqn. 5:

$\mathrm{r}_{\mathrm{CO}_{2}-\mathrm{R}_{1} \mathrm{R}_{2} \mathrm{NH}}=\mathrm{k}_{2}\left[\mathrm{R}_{1} \mathrm{R}_{2} \mathrm{NH}\right]\left[\mathrm{CO}_{2}\right]-\mathrm{k}_{-2}\left[\mathrm{R}_{1} \mathrm{R}_{2} \mathrm{NH}^{+} \mathrm{CO}^{-}\right](5)$

In the above reactions, the formation of zwitterion is the rate-determining step and the deprotonation step involves only proton transfer and is considered to be very fast. Therefore eqn. 5 is simplified to a second order reaction kinetics:

$$
\mathrm{r}_{\mathrm{CO}_{2}-\mathrm{R}_{1} \mathrm{R}_{2} \mathrm{NH}}=\mathrm{k}_{2}\left[\mathrm{R}_{1} \mathrm{R}_{2} \mathrm{NH}\right]\left[\mathrm{CO}_{2}\right]
$$

where $\mathrm{k}_{2}$ is second order reaction rate constant. Its value can be estimate from experimental data.

\section{Conclusion}

The absorption of $\mathrm{CO}_{2}$ into monoethanolamine, diethanolamine and piperazine solutions was studied experimentally. A series of tests was conducted for each absorbent at different concentration. It has been found that the best absorbents concentration should be selected from 40 to $50 \mathrm{wt} \%$. At the same temperature and concentration, monoethanolamine and diethanolamine both have a large absorption rate and capacity. The absorption reaction of ethanolamine solution can be interpreted using the zwitter-ion mechanism. Based on this mechanism, the total reaction is simplified to a second order reaction kinetics. The kinetics model is in good agreement with experimental data.

\section{ACKNOWLEDGEMENTS}

Financial support from the Natural Science Foundation of Guangxi (No. 2012GXNSFAA053025), Guangxi Higher Education Institutes Talent Highland Innovation Team Scheme (GJR201147-12) are gratefully acknowledged.

\section{REFERENCES}

1. S. Paul and K. Thomsen, Int. J. Greenhouse Gas Control, 8, 169 (2012).

2. H.R. Mortaheb, A.A. Nozaeim, M. Mafi and B. Mokhtarani, Chem. Eng. Sci., 82, 44 (2012).

3. J. Liu, Sh. Wang, B. Zhao, H. Tong and C. Chen, Energy Procedia, 1, 933 (2008)

4. J. Liu, Sh. Wang, G. Qi, B. Zhao and Ch. Chen, Energy Procedia, 4, 525 (2011)

5. A.F. Portugal, F.D. Magalhaes and A. Mendes, Chem. Eng. Sci., 63, 3493 (2008).

6. P.W.J. Derks, T. Kleingeld, C. van Aken, J.A. Hogendoorn and G.F. Versteeg, Chem. Eng. Sci., 61, 6837 (2006).

7. R. Maceiras, E. Alvarez and M. Cancela, Chem. Eng. J., 138, 295 (2008). 